\title{
Development of a Novel Control for a Matrix Converter Interfaced Wind Energy Conversion System for Dynamic Performance Enhancement
}

\author{
Vinod Kumar ${ }^{\mathrm{a}}$, Raghuveer Raj Joshi ${ }^{\mathrm{a}}$ \& Ramesh C. Bansal ${ }^{\mathrm{b}^{*}}$ \\ ${ }^{a}$ Department of Electrical Engineering, College of Technology and Engineering, Udaipur, India \\ ${ }^{b}$ Department of Electrical, Electronics and Computer Engineering, University of Pretoria, Pretoria, South Africa
}

\begin{abstract}
This article presents the development of a novel control for matrix converter interfaced permanent magnet wind energy conversion system. Here, an adaptive fuzzy control algorithm incorporated with a reversed matrix converter is proposed to yield maximum energy with enhanced dynamic performance and low harmonic characteristics. The control algorithm is implemented using a dSPACE DS1104 real-time board (dSPACE, Paderborn, Germany). Feasibility of the proposed system has been verified through simulation and experiment results using a laboratory $1.2-\mathrm{kW}$ prototype of a wind energy conversion system under dynamic conditions.
\end{abstract}

Keywords : matrix converter, synchronous generator, wind energy conversion system, wind turbine emulator

\section{Introduction}

In modern power supply systems, renewable power sources, particularly wind power, are becoming the most important worldwide. They are growing very fast with a capacity of around $360 \mathrm{GW}$ in December 2014 and are expected to achieve nearly $760 \mathrm{GW}$ by the year 2020 , in spite of several challenges faced by the wind industry, such as downward pressure on prices, increased competition among turbine manufacturers, and reductions in policy support driven by economic austerity [1].

For more output energy with less wind turbine cost, variable-speed operation is preferred for wind power generation. A doubly fed induction generator (DFIG) with a partial-scale power converter suffers from drawbacks of the use of slip rings and gearbox, which generally suffer from faults, making the system unreliable and costly, along with the challenging power controllability during grid faults [2-3]. In the very near future, the permanent magnet synchronous generator (PMSG) with a full-scale power converter will 
dominate in the market, as such a configuration is a preferred technology choice in the bestselling power ranges of the wind turbines [2-4], with better grid support ability and full power/speed controllability.

In [5], various power processing topologies were proposed and have investigated from time to time by different researchers. But all these suffer from the demerits of poor device utilization; the produced variable DC-link voltage causes distortion of currents and voltage of generator and has poor power factor operation. Out of these configurations, two commonly investigated matured alternatives for wind power generation purposes are the $A C / D C / A C$ converter [6-10] and the matrix converter (MC) [11-18]. Although the AC/DC/AC converter has a high energy density and is relatively low in price, there is a serious concern with its large DC-link capacitor due to its size, weight, volume, and premature failure [15, 17]. Also, these are sensitive to electromagnetic interference (EMI) and other noise signals that may lead to short-circuit fault.

In recent times, the $\mathrm{MC}$ has received a lot of attention by researchers for its application in wind power because of its high merit over traditional AC/DC/AC converters, as it is free from commutation problems, has improved voltage gain with simplified control, is compact in size, is light weight, and has high reliability due to the absence of a DC capacitor and extremely fast transient response [15]. Also, it provides the flexibility of more control levers for independent control on frequency, voltage magnitude, phase angle, and input power factor.

In such cases as a wind power system, an indirect $M C$, after some topological modifications with fewer unidirectional switches in reverse power flow mode, is of great interest rather than a traditional MC. Also, no additional passive components or step-up transformer will be required to achieve voltage boost function.

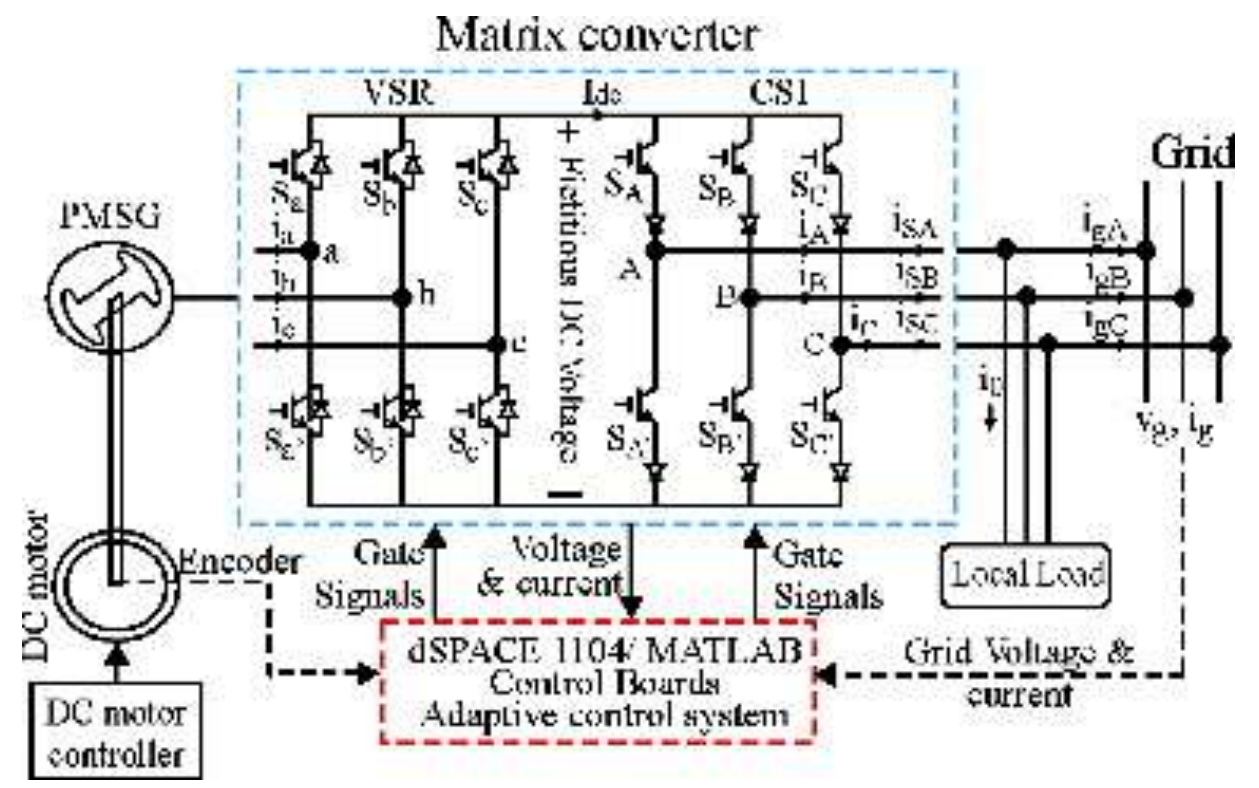

FIGURE 1. Block diagram of the proposed MC-interfaced WECS. 
Based on above merits of the PMSG with a unidirectional indirect reverse-connected MC, this work presents the development of adaptive fuzzy controls for an MC-interfaced wind energy conversion system (WECS). An adaptive fuzzy control together with space vector pulse-width modulation switching has been effectively implemented to enhance steadystate and dynamic performance under different conditions with maximum power tracking and low harmonic characteristics. The novelty of this work is that a reversed indirect MC with voltage-boosted capability and fewer switches compared to a traditional MC is experimentally investigated and validated with a laboratory $1.2-\mathrm{kW}$ prototype of the proposed system under steady-state and dynamic conditions. To the best knowledge of the authors, such a configuration for WECS applications have been neither addressed nor investigated experimentally before to achieve maximum power tracking with low harmonic characteristics.

\section{Proposed MC-Interfaced PMSG-Based WECS}

Figure 1 shows the block diagram of the proposed unidirectional indirect MC-interfaced WECS. The main advantages of the proposed WECS compared to the traditional WECS are low harmonic content, accommodation of large terminal voltage excursions, no limitation on input to output frequency ratio, wide frequency variations, and unbalanced grid conditions. Total harmonic distortion (THD) of output voltages and currents are in compliance with the permissible limits of Standards IEC 61727 and IEEE-519, which severely restrict line harmonic injection.

\subsection{Wind Turbine Model}

In this article, a wind turbine emulator that drives the generator is developed for laboratory tests. As can be seen in Figure 1, it consists of a DC drive, the control of which is implemented using the dSPACE DS1104 real-time board (dSPACE, Paderborn, Germany). It obtains the wind speed values and, by using the turbine characteristics and DC motor speed, calculates the torque command of the wind turbine. In this way, it reproduces the steady and dynamic behavior of a real wind turbine to the energy conversion system. Figure 2 presents the generated experimental plot of the output power versus generator speed for different wind speeds.

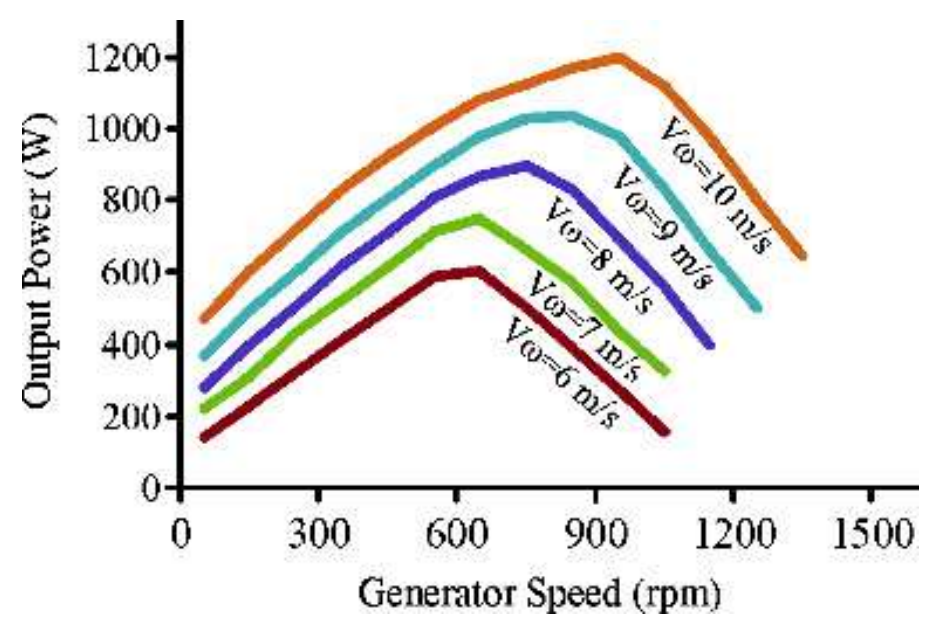

FIGURE 2. Experimental plot of generator speed versus output power for different wind speeds. 
The aerodynamic torque $\left(T_{m}\right)$ and power captured $\left(P_{0}\right)$ by a wind turbine is given by [17]

$$
\begin{aligned}
& \mathrm{T}_{\mathrm{m}}=0.5 \pi \rho \mathrm{C}_{\mathrm{p}}(\lambda) \mathrm{R}_{\omega}^{3} \mathrm{~V}_{\mathrm{w}}^{2}, \\
& \mathrm{P}_{0}=0.5 \rho \mathrm{C}_{\mathrm{p}} \mathrm{A}_{\mathrm{r}} \mathrm{V}_{\mathrm{w}}^{3},
\end{aligned}
$$

where $P_{0}$ is power (in watt), $C_{p}$ is a dimensionless factor called the power coefficient, $\rho$ is air density (in $\mathrm{kg} / \mathrm{m}^{3}$ ), $A_{r}$ is turbine rotor area (in $\mathrm{m}^{2}$ ), $V_{w}$ is wind speed (in $\mathrm{m} / \mathrm{s}$ ), and $R_{r}$ is rotor blade (in radius).

The power coefficient equation is expressed according to [19]

$$
\begin{aligned}
& \mathrm{C}_{\mathrm{p}}(\lambda, \theta) \\
& \quad=0.73\left(\frac{151}{\lambda_{\mathrm{i}}}-0.58 \theta-0.002 \theta^{2.14}-13.2\right) \mathrm{e}^{-18.4 / \lambda_{\mathrm{i}}},
\end{aligned}
$$

where

$$
\lambda_{i}=\frac{1}{\frac{1}{\lambda-0.02 \theta}-\frac{0.003}{\theta^{3}+1}}
$$

and

$$
\lambda=\frac{\omega_{\mathrm{m}} \mathrm{R}_{\mathrm{r}}}{\mathrm{V}_{\omega}},
$$

where $\lambda$ is the tip speed ratio, $\theta$ is rotor blade pitch angle, and $\omega_{m}$ is the angular speed of the turbine shaft. Substituting $V_{\omega}$ from Eq. (5) into Eq. (2) gives

$$
P_{0}=0.5 \rho C_{P} A_{r}\left(\frac{\omega_{m} R_{r}}{\lambda}\right)^{3} \text {. }
$$

Equation (6) depicts that by adjusting the shaft speed corresponding to the peak power for any wind speed, the maximum power can be captured from the wind. The novel idea explored here to achieve this is to change the angular frequency of the PMSG through space vector switching of voltage-boosted MC.

\subsection{Configuration of Voltage-boosted MC}

The schematic diagram of the unidirectional voltage-boosted MC with 12 switches, excluding the clamping circuit, is shown in dotted portion of Figure 1. As shown, six switches with anti-parallel diodes form the voltage source rectifier (VSR), whereas other six switches with series diodes for the current source inverter (CSI). It has its power flow from the VSR to CSI terminals, unlike a traditional MC. This reversal in power flow is important with respect to the wind generation system as these require voltage boosting of their source power

flowing to the grid/loads. 
At any instant, two switches each from upper and lower group conducts. An active state is formed when two conducting switches are from different legs, whereas an idle state results when conducting switches are from the same legs. During the active state, power is transferred to the load, whereas during the idle state, circulating current flows within the MC due to shorting of fictitious DC voltage to zero. Space vector representation of the CSI and VSR is presented in Figure 3 , showing total three idle and six active states. The detailed modulation algorithm has been explained in [13, 15, 20-23].

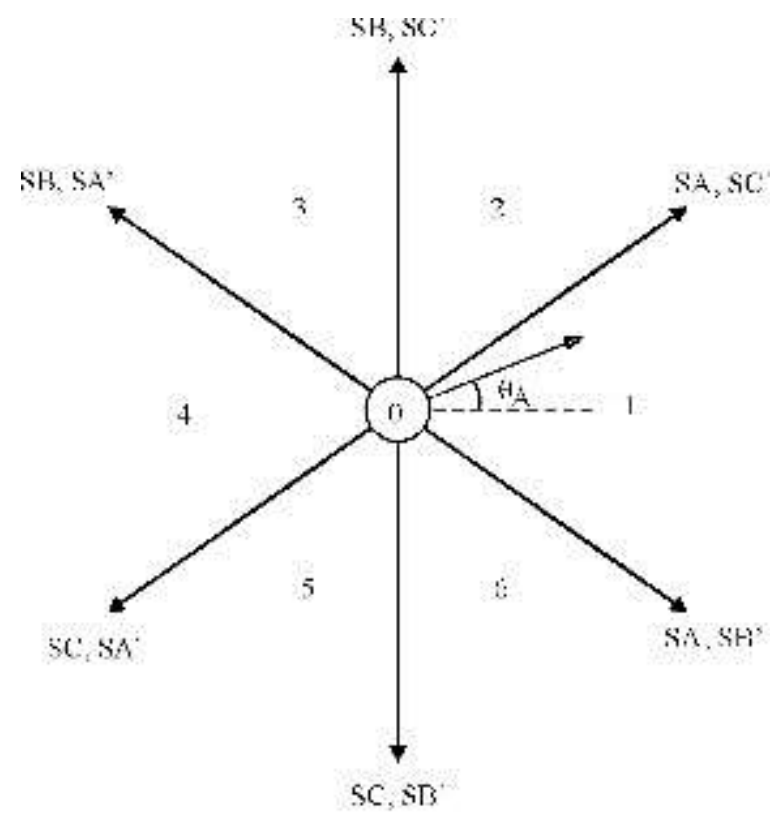

(a)

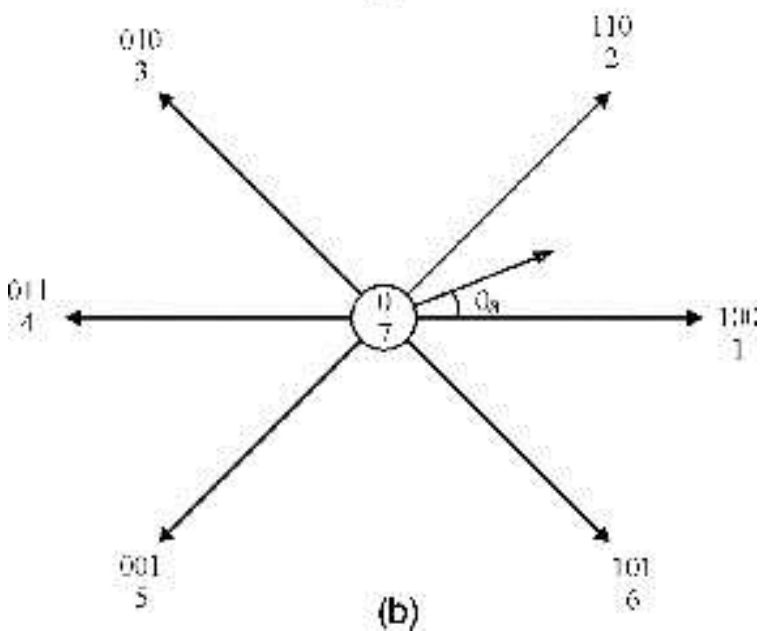

FIGURE 3. Space vector representation for CSI and VSR of MC: (a) CSI of MC and (b) VSR OF MC.

\subsection{Adaptive Fuzzy Control System (AFCS)}

As shown in Figure 1, the proposed control has adaptive fuzzy controllers to control the shaft speed and AC voltage, which is incorporated with the $M C$ to yield maximum power for any wind speed by regulating angular frequency of the generator. Figure 4(a) presents the schematic structure of the proposed AFCS. 
In this scheme, the value of angular frequency $\omega_{\text {ref }}$ is dynamically approached in real time from the fuzzy controller using a perturbation and observation type maximum power point tracking (MPPT) technique, which is explained as

Pertubtaion : $\omega_{\text {ref }}(t)=\omega_{\text {ref }}(t-1)+s\left|\Delta \omega_{\text {ref }}\right|$,

Observation : $\Delta P_{0}=P_{0}(t)-P_{0}(t-1)$,

where

1. $\omega_{\text {ref }}(t)$ is the actual angular frequency sampling,

2. $\omega_{\text {ref }}(t-1)$ is the previous angular frequency sampling,

3. $\left|\Delta \omega_{\text {ref }}\right|$ is the step of angular frequency disturbance,

4. $\Delta P_{0}$ is the difference of power,

5. $P_{0}$ is the output power,

$6 . * * * 8710 \delta$ is the phase shift of phase angle,

7. $R F$ is the regulating factor of fuzzy controller membership

8. functions (MFs), and $\sigma$ is the variance of $\omega_{e}$.

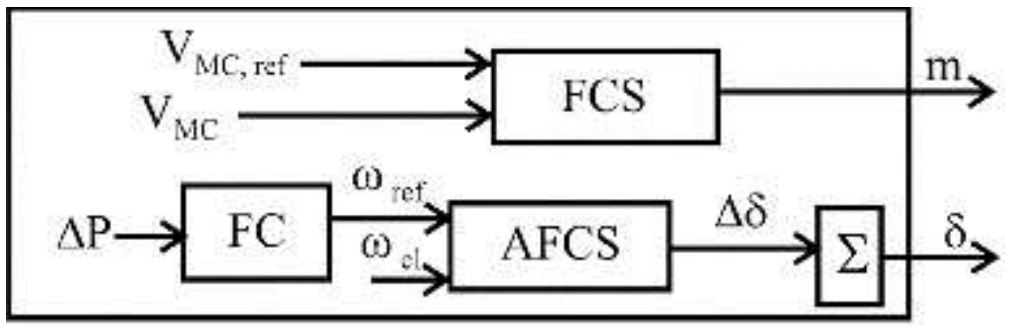

(a)

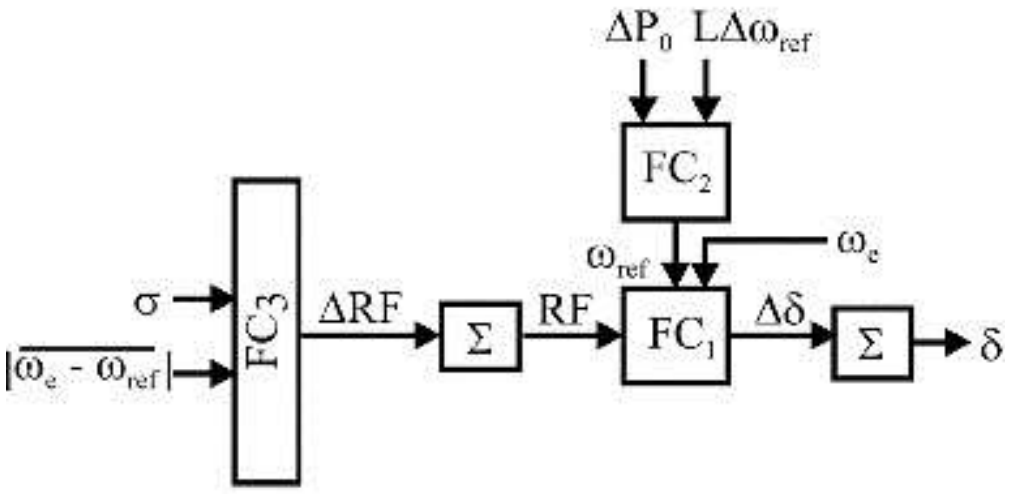

(b)

FIGURE 4. Structure: (a) of proposed control system and (b) AFCS.

This is achieved by disturbing the actual angular frequency by amount $* * * 8710 \omega_{\text {ref }}$ and then monitoring the corresponding change in output power $\Delta P_{0}$, which is estimated according to corresponding increment (or decrement) of $\omega_{\text {ref. If }} * * * 8710 P_{0}$ is positive, then the search is continued in the same direction; otherwise, the direction of the search is reversed. The MC successfully achieves the maximum power by regulating the active power through modulating its phase angle $(\delta)$. 


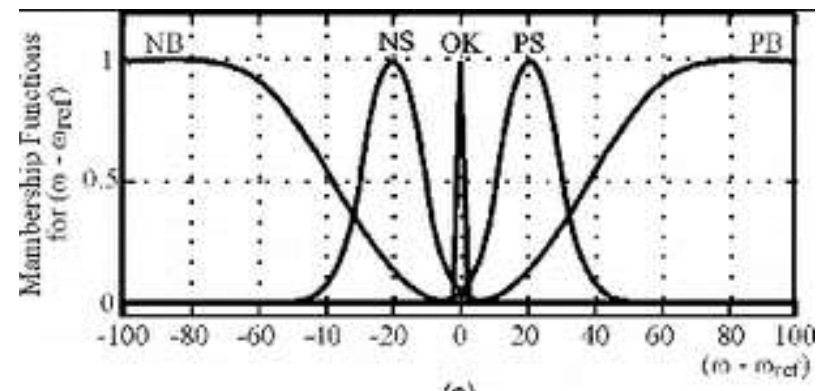

(a)

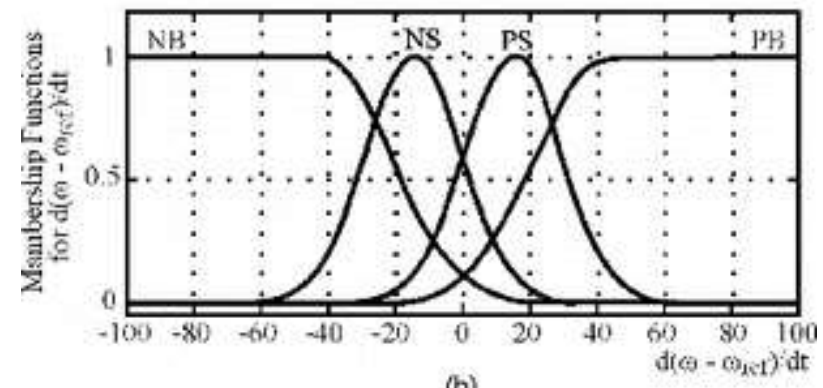

(b)

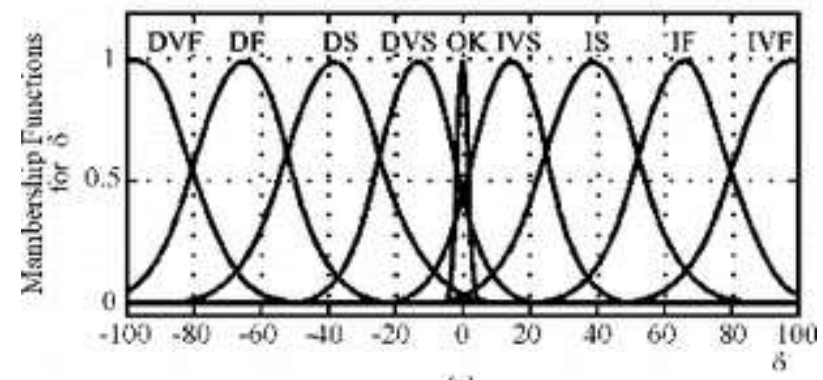

(c)

FIGURE 5. MFs for the fuzzy set $\omega_{e}-\omega_{\text {ref }}$, derivative of $\omega_{e}-\omega_{\text {ref, }}$ and phase angle $\delta$.

As shown in Figure 4(b), the AFCS consists of three fuzzy controllers: $\mathrm{FC}_{1}$, which is the main controller, $\mathrm{FC}_{2}$, the role of which is to dynamically detect on-line angular frequency corresponding to the maximum power and efficiency, and $\mathrm{FC}_{3}$, the role of which is to finetune $\mathrm{FC}_{1}$. The angular frequency of the generator is monitored and compared with the current reference value, and the error is then sent to fuzzy controller $\mathrm{FC}_{1}$, which produces a signal $* * * 8710 \delta$. In this way, by accumulating successive values of $* * * 8710 \delta$, a new value of $\delta$ is produced as

$\delta^{\text {new }}=\delta^{\text {old }}+\Delta \delta$

where $\delta^{\text {new }}$ and $\delta^{\text {old }}$ are the new and old values of phase angle $\delta$. For example, when the AFCS detects that value of electrical frequency $\omega_{e}$ is below the optimal value, it generates a negative value of phase angle "***8710 $\delta$ " for the MC, which results in a decrease of $\delta$ and less power absorbed as closed-loop control commands the decrease of excitation current, which in turn reduces the air-gap magnetic field. 
The MFs for fuzzy set $\omega_{e}-\omega_{\text {ref, }}$ derivatives of $\omega_{e}-\omega_{\text {ref, }}$, and phase angle $\delta$ are shown in Figure 5. As shown, the five fuzzy subsets needed for input $\omega_{e}-\omega_{\text {ref }}$ are negative big (NB), negative small (NS), OK, positive small (PS), and positive big (PB), whereas the four fuzzy sets for the derivative of $\omega_{e}-\omega_{\text {ref, }}$ are NB, NS, PS, and PB. The fuzzy sets needed for phase angle $\delta$ are decrease very fast (DVF), decrease fast (DF), decrease slowly (DS), decrease very slowly (DVS), OK, increase very slowly (IVS), increase slowly (IS), increase fast (IF), and increase very fast (IVF).

Control algorithm has been developed in the MATLAB/Simulink (The MathWorks, Natick, Massachusetts, USA) programming environment using the dSPACE DS1104 kit.

\section{Results and Discussion}

Figure 6 illustrates the schematic of the laboratory 1.2-kW prototype of the proposed MCinterfaced WECS. It has been built using MATLAB/Simulink and dSPACE DS1104 to allow real-time control during experimental evaluation of the proposed system under different steady-state and dynamic conditions. Selected simulation and experimental results are discussed below for varying wind and load conditions.

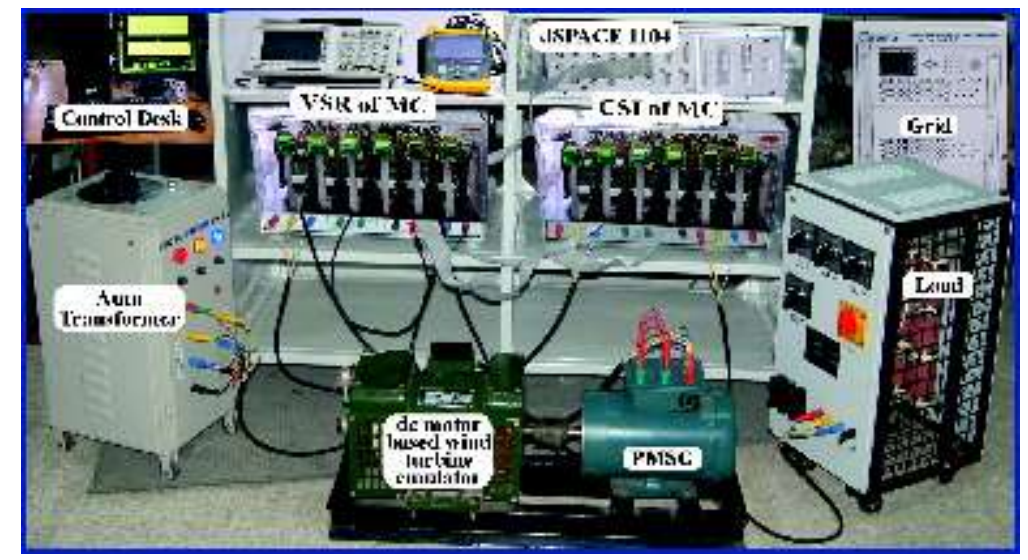

FIGURE 6. Schematic of the developed laboratory prototype.

\subsection{Response During Varying Load Condition}

To validate the proposed adaptive control based MC-interfaced WECS, the laboratory prototype is also tested under varying non-linear inductive load conditions. Figures 7 and 8 illustrate the simulated and experimental dynamic response of the proposed system under varying load transient conditions.

As shown in Figure 7, the load is changed from full load to half load and then to full load. Examining the waveforms in Figures 7(b), 7(c), 8(b), and 8(c), it is verified that when the load is changed to a smaller value, the load current is decreased, and so closed-loop control commands the necessary control action to maintain the voltage magnitude constant.

On the other hand, when the load is changed to a larger value, the load current is increased and the controller keeps the load voltage constant, as expected. During these actions, it can be observed in Figures $7(\mathrm{~g})$ and $8(\mathrm{f})$ that the proposed adaptive fuzzy controller dynamically 

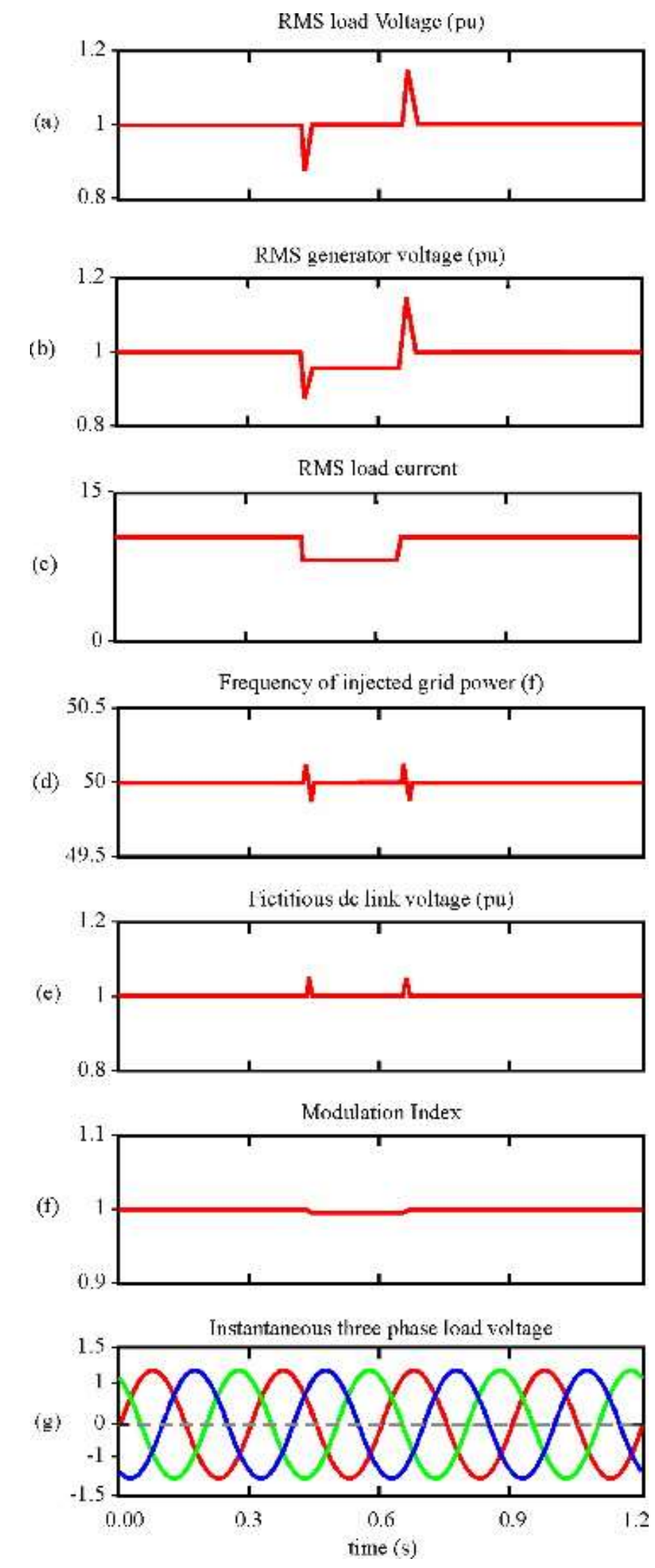

FIGURE 7. Simulated waveform during varying load condition with proposed control: (a) RMS load voltage, (b) RMS generator voltage, (c) RMS load current, (d) frequency of injected grid power, (e) fictitious DC-link voltage, (f) modulation index, and (g) instantaneous three-phase grid voltage. 
(a)

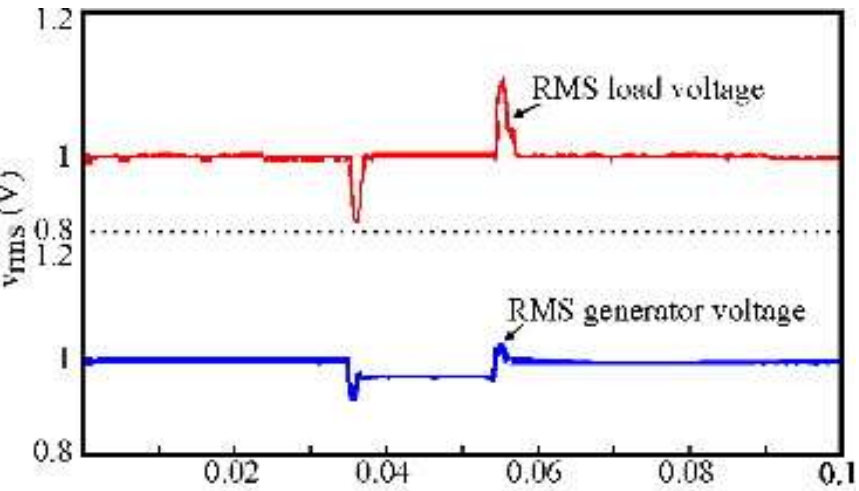

(b)

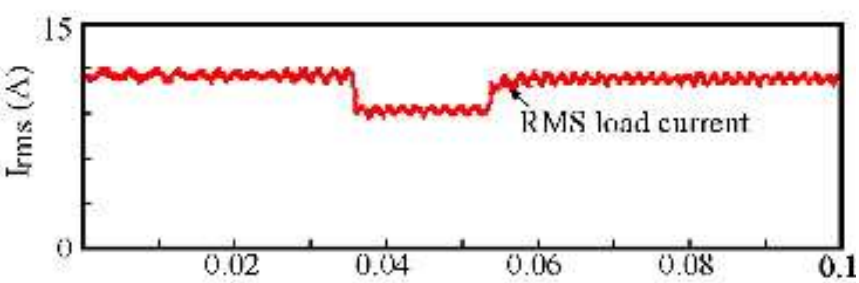

(c)
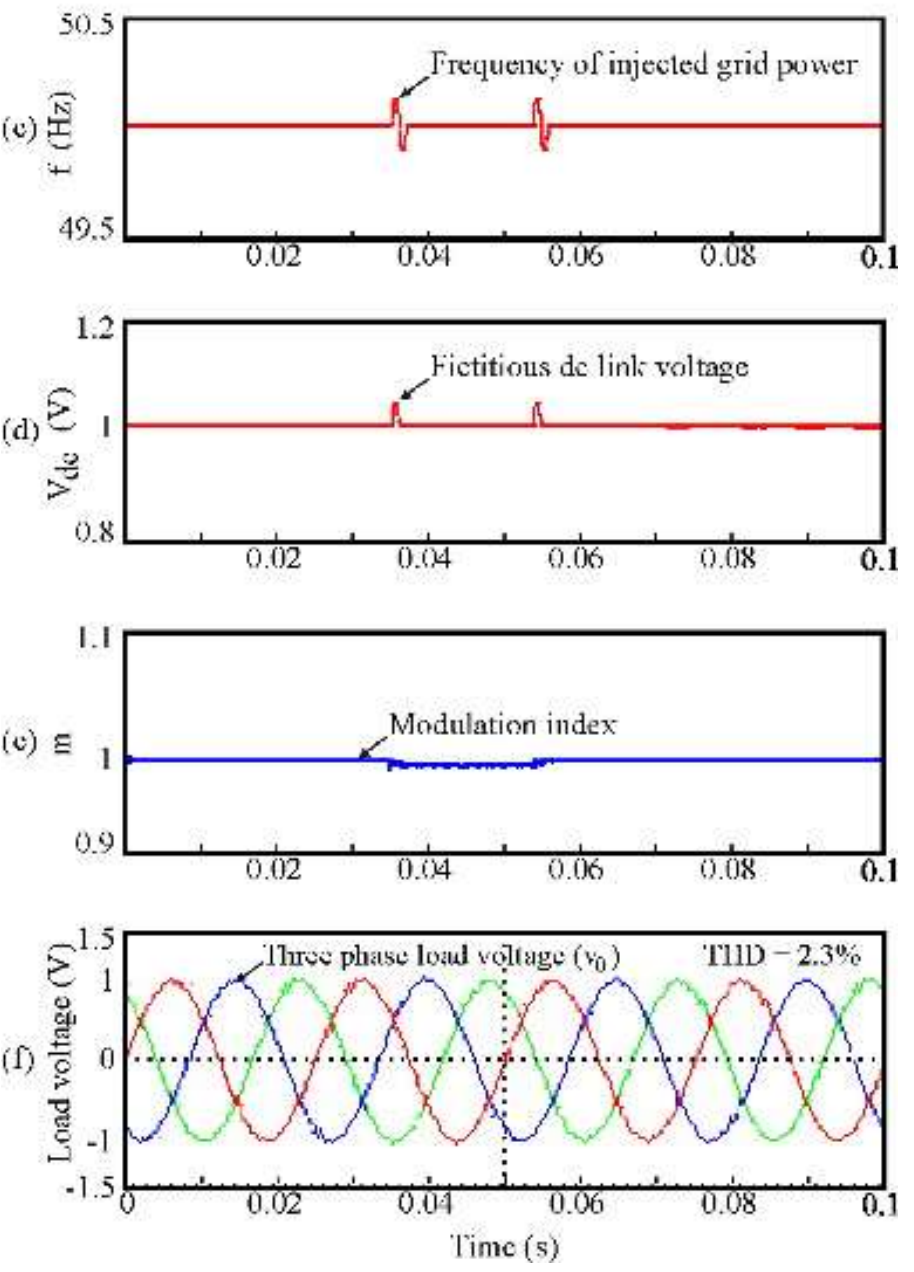

FIGURE 8. Experimental waveform during varying load condition: (a) RMS load voltage and RMS generator voltage, (b) RMS load current, (c) frequency of injected grid power, (d) fictitious DC-link voltage, (e) modulation index, and ( $f$ ) instantaneous three-phase grid voltage response when the load changes from full load to half load and from half load to full load. 

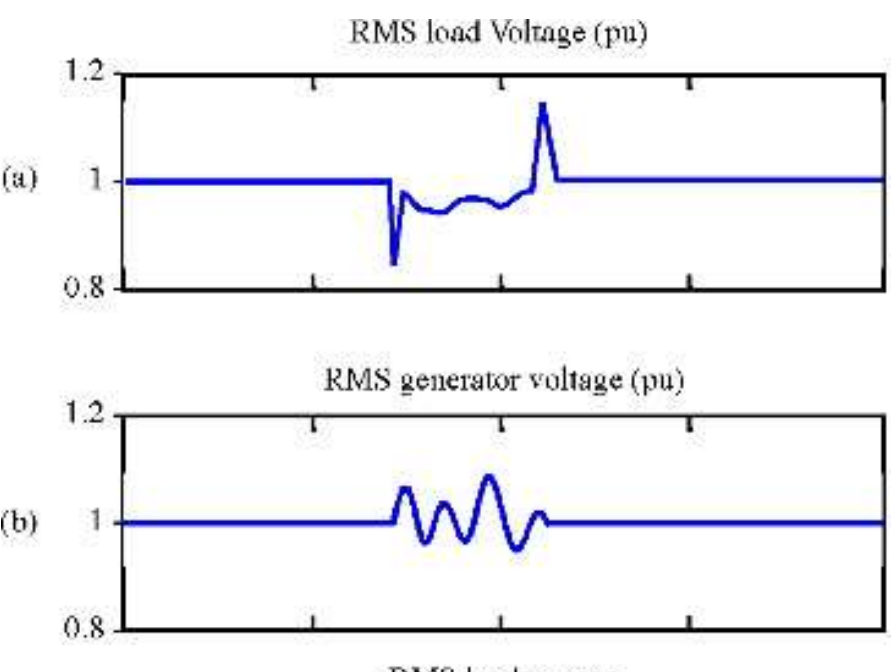

(c)
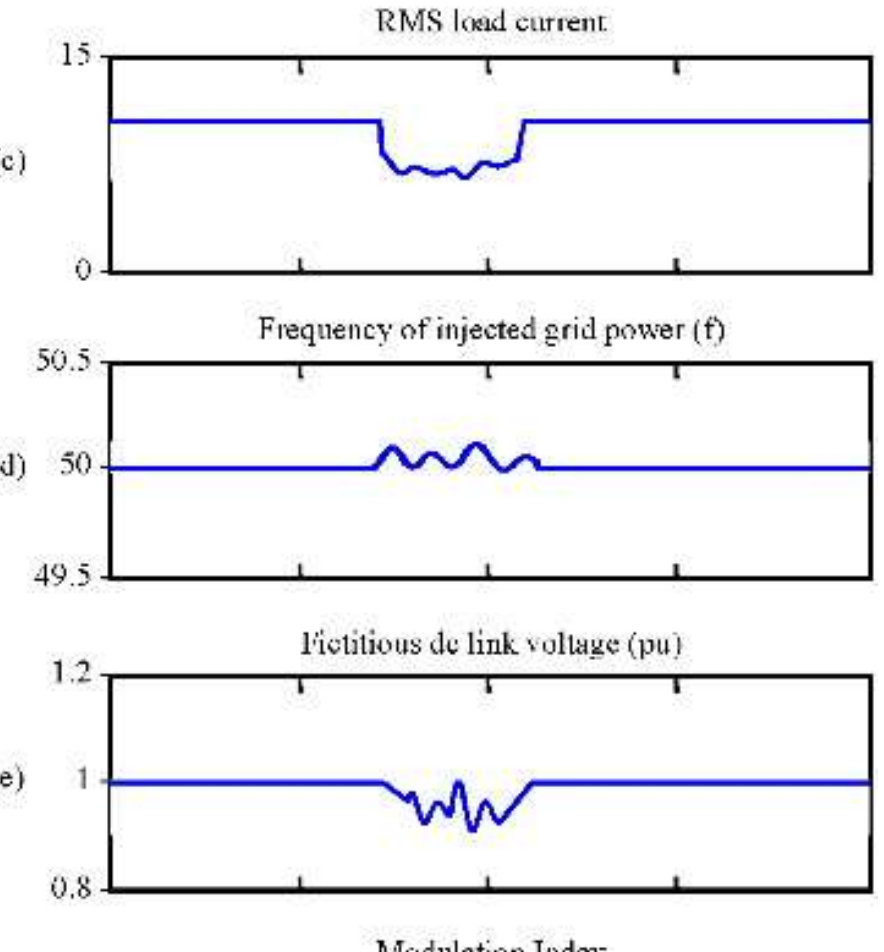

(t)
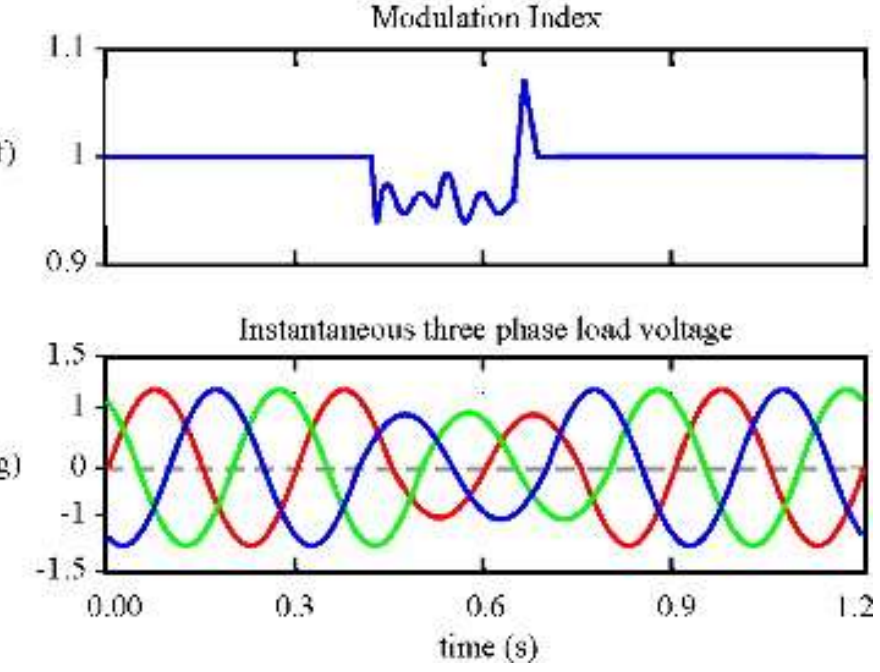

FIGURE 9. Simulated waveform during varying load conditions with conventional PI control: (a) RMS load voltage, (b) RMS generator voltage, (c) RMS load current, (d) frequency of injected grid power, (e) fictitious DC-link voltage, (f) modulation index, and (g) instantaneous three-phase grid voltage. 
adjusts the reference output current of the $M C$ to regulate the load voltage at the desired value.

The simulation and experimental results indicate that the proposed control system is quite able to stabilize the load voltage under varying load conditions by regulating the modulation index of the $\mathrm{MC}$, thus evaluating and exploring the disturbance rejection capability. From both simulation and experimental results, it is evident that the output voltage and frequency are well maintained despite variation in loads, whereas the load current is changing with load variation, as expected.

The response of the system with conventional proportional-integral (PI) control is shown in Figure 9 for varying load conditions, where it can be seen that conventional control takes no appropriate action for the mitigation of the fluctuations during load variations. Also, the overall response of the system with conventional control is more sluggish and fluctuating, thus validating the superiority of the proposed control over conventional.

\subsection{Response Under Varying Wind Speeds}

To illustrate the maximum power point (MPP) tracking capability of the proposed adaptive fuzzy logic based controller, the developed WECS prototype is tested under varying wind conditions. The simulated and experimental results for wind speed $(v)$, generator speed $\left(\omega_{r}\right)$, injected grid currents $\left(i_{g A}, i_{g B}, i_{g C}\right)$, grid active power $\left(P_{g}\right)$, grid phase voltages $\left(v_{g A}, v_{g B}, v_{g c}\right)$, grid frequency $(f)$, and power factor $(p f)$ are shown in Figures 10 and 11 , respectively.

As shown in the experimental waveforms of Figure 11, the applied torque command to the prime mover corresponds to a wind speed of $7.5 \mathrm{~m} / \mathrm{s}$, which runs the generator at 115 $\mathrm{rad} / \mathrm{s}$. At $t=0.033 \mathrm{sec}$, a step change in wind speed is commanded to the prime mover corresponding to wind speed of $12 \mathrm{~m} / \mathrm{s}$ as, shown. In response to this, generator speed and angular frequency also increase and settle at a new value of $156 \mathrm{rad} / \mathrm{s}$. The corresponding change in injected grid current, grid voltage, and power can also be noticed from Figures 11(c)-11(e). From Figure 11(b), it is evident that THE generator follows the angular frequency for maximum aerodynamic efficiency $\left(\omega_{\text {ref }}\right)$ to achieve the MPP very closely. Also, the $A C$ voltage regulator of adaptive fuzzy control keeps the $M C$-injected grid voltage regulated, as verified in Figure 11(e).

With the increase or decrease of prime mover speed, adaptive fuzzy control generates phase shift signal $* * * 8710 \delta$ of phase angle $\delta$ through the fuzzy controller, after comparing frequencies $\omega_{e}$ with $\omega_{\text {ref. }}$ In this way, new values of phase angle $(\delta)$ and modulation index $(m)$ are produced to operate at maximum aerodynamic efficiency to yield maximum power and regulated output grid voltage, respectively. Similarly, at $t=0.063 \mathrm{sec}$, a step change in wind speed is commanded back to $7.5 \mathrm{~m} / \mathrm{s}$, as shown in Figure 11(a). The respective change in generator speed, current, power, and voltage can be noticed from Figures 11(b)-11(e). From the results, it is evident that the developed adaptive fuzzy based MPPT scheme effectively tracks the MPP under fluctuating wind speed conditions to yield maximum energy. 
(a)

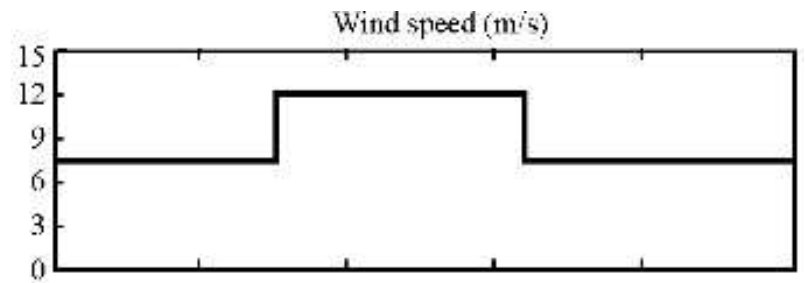

Angular speed (rad:s)

(b)

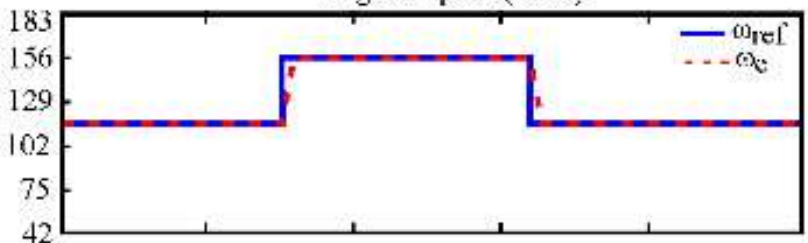

(c)

Injectwe grid current (A)

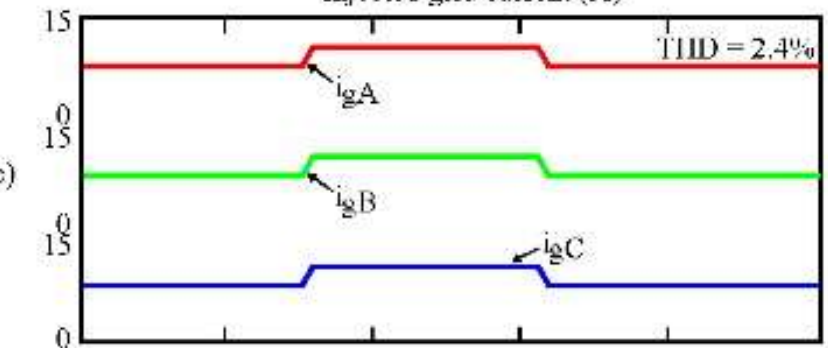

Injecled grid aclive power (kW)

(d)

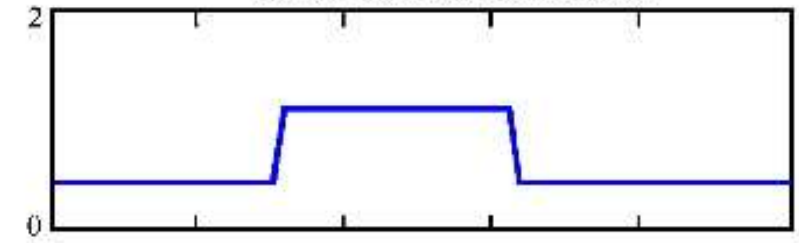

Grid voltage (V)

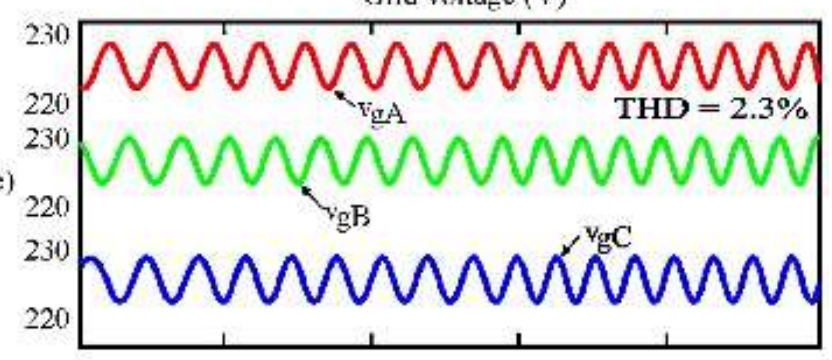

Frequency of injected grid power $(\mathrm{H}>)$

(t)

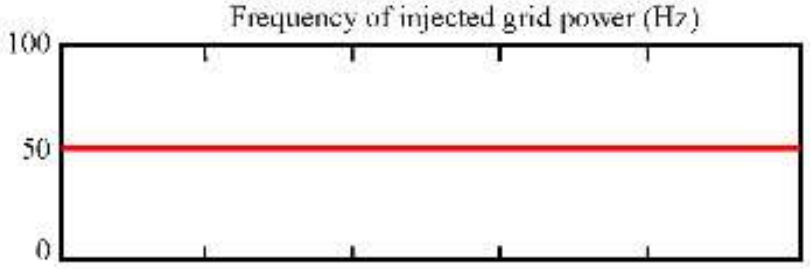

(g)

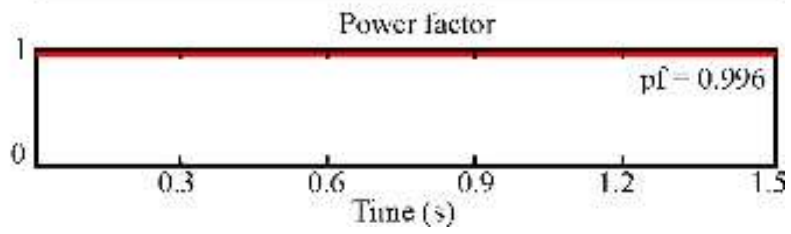

FIGURE 10. Simulated waveform during varying wind conditions: (a) wind speed ( $v$ ), (b) generator speed $\left(\omega_{e 1}\right),(\mathrm{c})$ injected grid currents $\left(i_{g A}, i_{g B}, i_{g c}\right),(\mathrm{d})$ grid active power $\left(P_{g}\right),(\mathrm{e})$ grid phase voltages $\left(v_{g A}, v_{g B}, v_{g c}\right),(f)$ grid frequency $(f)$, and $(g)$ power factor $(p f)$. 
(a)

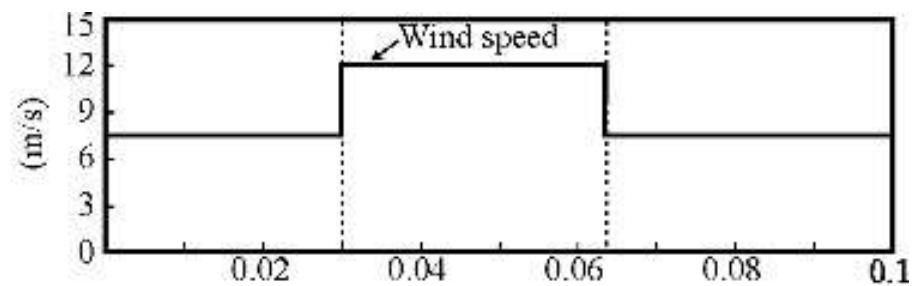

(b)

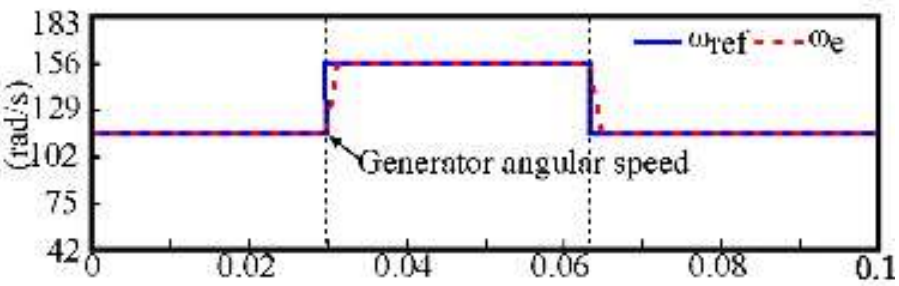

(c)

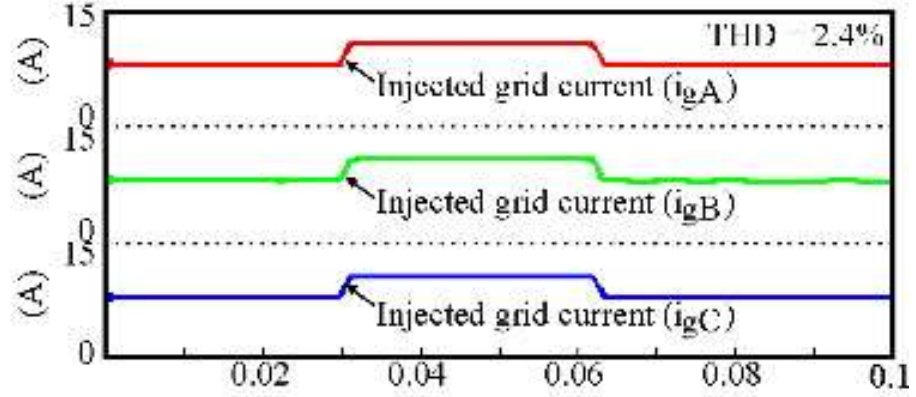

(d)

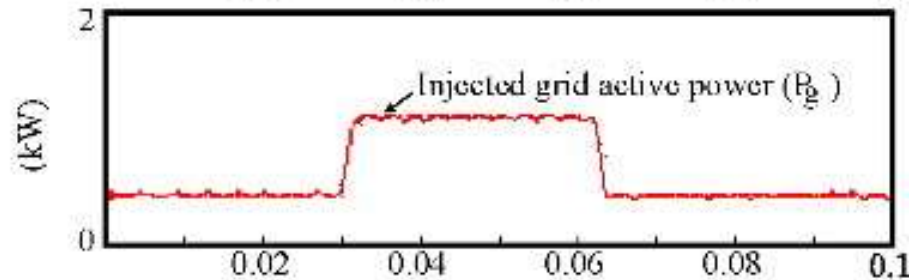

(e)

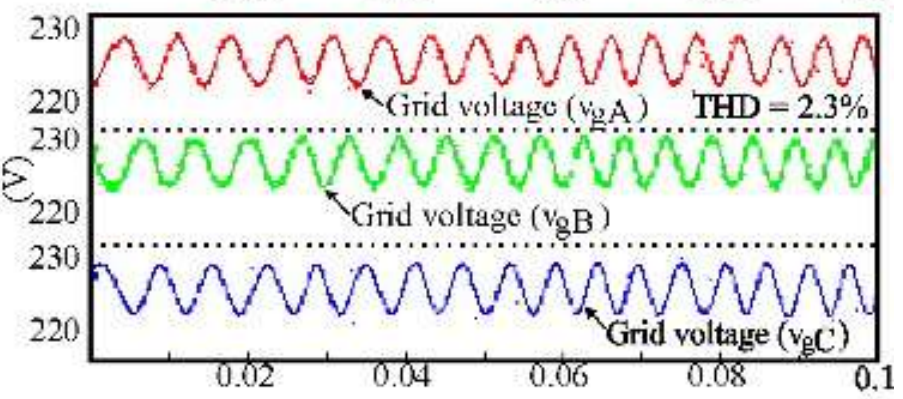

(i)

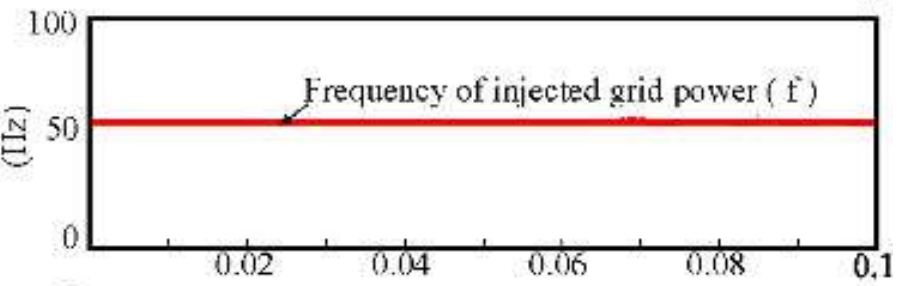

(g)

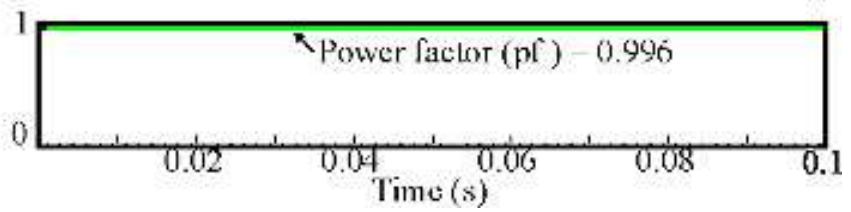

FIGURE 11. Experimental waveform during varying wind conditions: (a) wind speed $(v)$, (b) generator speed $\left(\omega_{e 1}\right)$, (c) injected grid currents $\left(i_{g A}, i_{g B}, i_{g c}\right)$, (d) grid active power $\left(P_{g}\right)$, (e) grid phase voltages $\left(v_{g A}, v_{g B}, v_{g c}\right)$, (f) grid frequency $(f)$, and $(g)$ power factor $(p f)$. 
Figures 11 (c) -11 (e) illustrate that the THD measured for injected grid current and voltage is $2.4 \%$ and $2.3 \%$, respectively, which is quite low per Standard IEEE-519 and IEC 61727. Also, it satisfies the power factor demand with a 0.996 power factor, as illustrated in Figure 11(g), and is far better as compared to power factor and THD of about $0.94 \%$ and $4.25 \%$, respectively, in the case of the converter topology proposed for wind power applications by Oliveira et al. in [5]. This demonstrates the expected improvement when compared with similar works in $[3,5,18]$. From the results of Figures $11(\mathrm{e})-11(\mathrm{~g})$, it is clear that the proposed adaptive control effectively maintains the constant voltage and frequency of the MC-injected grid power and power factor under varying wind conditions, and experimental results are in compliance with the simulated results.

\section{Conclusion}

The proposed adaptive fuzzy' controller is capable of maximizing output power from winds with enhanced dynamic performance under varying load and wind conditions. Both simulation and experimental results validate that the developed controller effectively regulates the grid voltage and frequency under varying wind and load conditions. Also, the output current and voltage of the MC injected to the grid strictly satisfies Standards IEC 61727 and IEEE, thus showing excellent enhanced dynamic response with low harmonic characteristics. It is found that experimental results are in compliance with simulated results, showing superior performance compared with conventional control.

\section{References}

1. REN21, "Renewables 2013 global status report," available at: http://www.ren21.net

2. Blaabjerg, F., and Ke, M., "Future on power electronics for wind turbine systems," IEEE J. Emerging Selected Topics Power Electron., Vol. 1, No. 3, pp. 139-152, September 2013.

3. Abdel-Salam, M., Ahmed, A., and Abdel-Sater, M., "Harmonic mitigation, maximum power point tracking, and dynamic performance of variable-speed grid-connected wind turbine," Electr. Power Compon. Syst., Vol. 39, No. 2, pp. 176-190, 2011.

4. Li, S., Haskew, T.A., Swatloski, R.P., and Gathings, W., "Optimal and direct-current vector control of direct-driven PMSG wind turbines," IEEE Trans. Power Electron., Vol. 27, No. 5, pp. 2325-2337, May 2012.

5. Oliveira, D.S., Reis, M.M., Silva, C.E. A., Colado Barreto, L.H. S., Antunes, F.L. M., and Soares, B.L., "A three-phase high frequency semicontrolled rectifier for PM WECS," IEEE Trans. Power Electron., Vol. 25, No. 3, pp. 677-685, March 2010.

6. Portillo, R.C., Prats, M.M., and Leon, J.I., "Modeling strategy for back-to-back three-level converters applied to high-power wind turbines," IEEE Trans. Ind. Electron., Vol. 53, No. 5, pp. 1483-1491, 2006.

7. Espi, J.M., and Castello, J., "Wind turbine generation system with optimized DC-link design and control," IEEE Trans. Ind. Electron., Vol. 60, No. 3, pp. 919-929, March 2013. 
8. Rodriguez, P., Timbus, A.V., Teodorescu, R., Liserre, M., and Blaabjerg, F., "Flexible active power control of distributed power generation systems during grid faults," IEEE Trans. Ind. Electron., Vol. 54, No. 5, pp. 2583-2592, 2007.

9. Teodorescu, R., and Blaabjerg, F., "Flexible control of small wind turbines with grid failure detection operating in stand-alone and grid-connected mode," IEEE Trans. Power Electron., Vol. 19, No. 5, pp. 1323-1332, September 2004.

10. Muller, S., Deicke, M., and De Doncker, R.W., "Doubly fed induction generator systems for wind turbine," IEEE Ind. Appl. Mag., Vol. 8, No. 3, pp. 26-33, 2002.

11. Garceés, A., and Molinas, M., "A study of efficiency in a reduced matrix converter for offshore wind farms," IEEE Trans. Ind. Electron., Vol. 59, No. 1, pp. 184-193, January 2012.

12. Hojabri, H., Mokhtari, H., and Chang, L., "Reactive power control of permanent-magnet synchronous wind generator with matrix converter," IEEE Trans. Power Del., Vol. 28, No. 2, pp. 575-584, April 2013.

13. Nikkhajoei, H., and Iravani, M., "A matrix converter based micro-turbine distributed generation system," IEEE Trans. Power Del., Vol. 20, No. 3, pp. 2182-2192, July 2005.

14. Cárdenas, R., Pena, R., Clare, J., and Wheeler, P., "Analytical and experimental evaluation of a WECS based on a cage induction generator fed by a matrix converter," IEEE Trans. Energy Convers., Vol. 26, No. 1, pp. 204-215, March 2011.

15. Kumar, V., Joshi, R.R., and Bansal, R.C., "Optimal control of matrix-converter-based WECS for performance enhancement and efficiency optimization," IEEE Trans. Energy Convers., Vol. 24, No. 1, pp. 264-273, March 2009.

16. Barakati, S.M., Kazerani, M., and Aplevich, J.D., "Maximum power tracking control for a wind turbine system including a matrix converter," IEEE Trans. Energy Convers., Vol. 24, No. 3, pp. 705-713, September 2009.

17. Kumar, V., Joshi, R.R., and Bansal, R.C., "Experimental evaluation of matrix converter for wind energy conversion system under various abnormal conditions," Int. J. Renew. Energy Res., Vol. 4, No. 1, pp. 15-22, 2014.

18. Karaman, E., Farasat, M., and Trzynadlowski, A.M., "Permanent-magnet synchronousgenerator wind-energy systems with boost matrix converters," Proceedings of IEEE Energy Conversion Congress and Exposition, pp. 2977-2981, Denver, CO, 15-19 September 2013.

19. Slootweg, J.G., de Haan, S.W. H., Polinder, H., and Kling, W.L., "General model for representing variable speed wind turbines in power system dynamics simulations," IEEE Trans. Power Syst., Vol. 18, No. 1, pp. 144-151, February 2003.

20. Gao, F., and Iravani, M.R., "Dynamic model of a space vector modulated matrix converter," IEEE Trans. Power Del., Vol. 22, No. 3, pp. 1696-1705, July 2007. 
21. Chang, J., Sun, T., and Wang, A., "Highly compact AC-AC converter achieving a high voltage transfer ratio," IEEE Trans. Ind. Electron., Vol. 49, No. 2, pp. 345-352, April 2002.

22. Wheeler, P.W., Rodríguez, J., Clare, J., Empringham, L., and Weinstein, A., "Matrix converters: A technology review," IEEE Trans. Power Electron., Vol. 49, No. 2, pp. 276-289, April 2002.

23. Liu, X., Loh, P.C., Wang, P., Blaabjerg, F., Tang, Y., and Al-Ammar, E.A., “Distributed generation using indirect matrix converter in reverse power mode," IEEE Trans. Power Electron., Vol. 28, No. 3, pp. 1072-1082, March 2013. 